\begin{tabular}{cc}
\hline & International Journal of Medicine, $8(1)(2020) 1-3$ \\
SPC & International Journal of Medicine \\
Website: $w w w . s c i e n c e p u b c o . c o m / i n d e x . p h p / I J M$ & Research paper \\
\hline
\end{tabular}

\title{
Osteopoikilosis: Rare case with incidental radiographic findings
}

\author{
Azin Azarfar ${ }^{1}$, Hiffsa Taj ${ }^{1}$, Michael Seifert ${ }^{2}$ \\ ${ }^{1}$ University of Central Florida HCA GME Healthcare, Greater Orlando, FL \\ ${ }^{2}$ Department of Internal Medicine, University of Central Florida College of Medicine, Orlando, FL \\ *Corresponding author E-mail: azin.azarfar@ucf.edu
}

\begin{abstract}
We report a case of benign, autosomal dominant, sclerosing dysplasia of bone in a 41-year-old man. This is a very rare disorder characterized by numerous, symmetric, homogenous bone islands. The disease is mainly asymptomatic and requires no treatment.

Keywords: Osteopoikilosis, Sclerosing, Bone Lesions, Benign.

\section{Introduction}

Osteopoikilosis, also known as "spotted bone disease" is a benign, rare autosomal dominant sclerosing dysplasia of bone characterized by the presence of numerous bone islands in the skeleton and is mainly discovered incidentally on radiographs [1]. It is usually asymptomatic. The osteosclerotic dysplasia of bones develops during childhood and persists throughout life [2]. It is equally distributed among males and females and can occur at any age.

The bone islands of osteopoikilosis are small, clearly defined densities of oval or rounded shapes in the appendicular skeleton typically clustered around joints with a linear pattern of distribution along the long axis of limbs [3,4]. Due to its close resemblance with other bone lesions such as osteoblastic metastasis, it must be considered in the differential diagnosis to avoid unnecessary investigations.
\end{abstract}

\section{Case}

41-year-old right-handed gentleman with a past medical history of lumbar stenosis, hypertension, and obesity presented to a sport medicine clinic with progressively worsening right shoulder pain for four months prior to presentation. It had begun to affect his performance at work and had led to functional limitations in overhead activities, gripping, lifting, and carrying. He was working at a water restoration company, and his job required occasional lifting of objects up to 100 pounds. He denied any other physical or constitutional symptoms, skin lesions or joint involvement. His social history is pertinent for tobacco use. His medications included Lisinopril, Ibuprofen, topical Diclofenac, and vitamin D supplement.

On physical examination, his vital signs were stable. He was in no acute distress and appeared otherwise healthy. The shoulder exam was notable for an absence of skin lesions or rashes. The right shoulder was normal in appearance with good muscle tone. There was tenderness to palpation anterior to the glenohumeral joint. The range of motion was full in all planes of motion. Muscle strength on the right shoulder was decreased to 4 out of 5 in abduction and external rotation but was otherwise full. The Hawkins-Kennedy, Empty Can, and O'Brien's labral test were all positive on the right side. Negative findings noted on the exam included Neer's, Speed's, and Yergason's tests. The contralateral shoulder exam was normal.

Based on his exam and history, he was diagnosed with right rotator cuff tendinopathy. A sub-acromial steroid injection and physical therapy referral were planned. Before the injection, a 4-view radiograph of his shoulder was obtained. The radiographs showed well defined, widespread, multiple densities scattered throughout the right proximal humeral head, humeral metaphysis, and glenoid (Figures 1-3). 


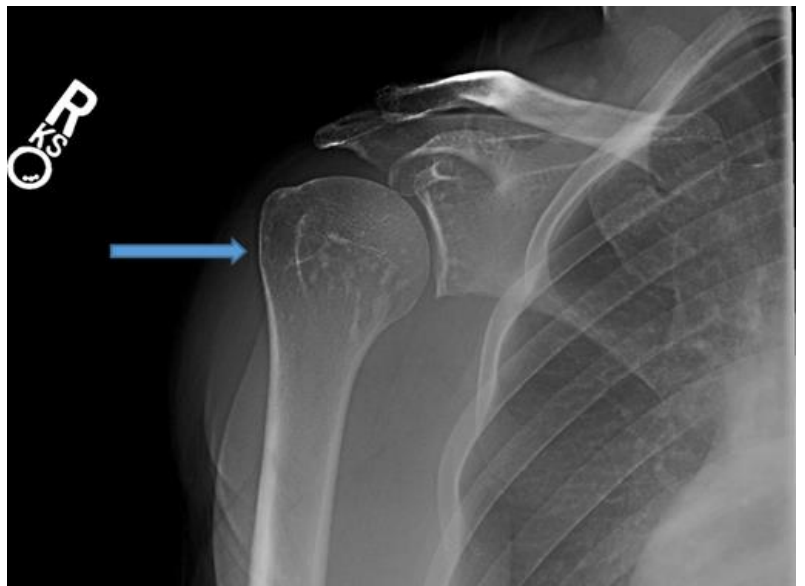

Fig. 1: AP Glenoid View Showing Radio-Opaque Densities (Arrow) in the Right Humerus and Glenoid.

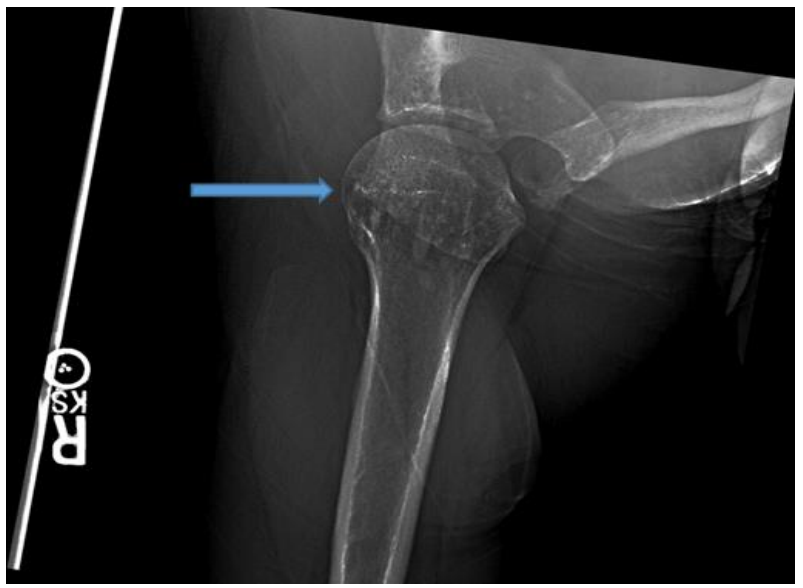

Fig. 2: Axillary View Again Revealing Densities (Arrow) in Right Humerus and Glenoid.

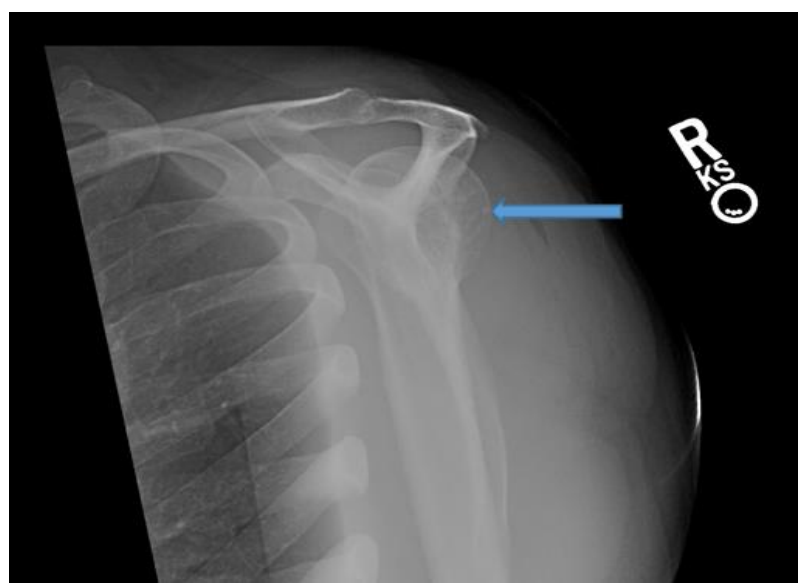

Fig. 3: Scapular Y View with Densities (Arrow) of Right Humeral Head Evident Laterally.

The abnormal appearance of his radiographs prompted a discussion of his case with a musculoskeletal radiologist, and given the typical radiographic findings (pepper-pot/spotted bone), as well as lack of concerning symptoms for alternative etiologies, the diagnosis of osteopoikilosis was made.

The patient proceeded to receive the subacromial steroid injection and was referred to physical therapy for muscular retraining and stabilization. He reported to the therapist that he had a significant reduction in shoulder pain after the steroid injection. He attended the initial physical therapy session but was lost to follow up.

\section{Discussion}

Osteopoikilosis is a rare and benign disorder of sclerosing bone dysplasia that is transmitted in an autosomal dominant pattern. It is caused by the failure of resorption of secondary spongious bone [5]. The pathogenesis of osteopoikilosis is not well known, but multiple hypotheses have been proposed in the literature [1]: a hereditary failure to form normal trabeculae along lines of stress [2], dysplasia of endochondral ossification [6], loss of function mutations in LEMD3 gene and abnormal osteogenesis [7]. Since osteopoikilosis is an incidental finding, it is difficult to estimate its prevalence in the general population [8]. Around 1955, E. Jonasch, reviewed 210,000 X-ray imagings and found 12 to have findings compatible with osteopoikilosis, then he estimated the prevalence to be $1 / 50,000$ among general population [5, 9].

Osteopoikilosis lesions are numerous, widespread, symmetric, homogenous, dense lesions that usually involve the appendicular skeleton and rarely the axial skeleton. The most commonly involved areas in order of prevalence are phalanges of the hand, metacarpals, foot 
phalanges, metatarsals, tarsal bones, pelvis, femur, radius, ulna, sacrum, humerus, tibia, and fibula. These lesions are usually bilateral and more frequently occur in the metaphysis of long bones [6]. The diagnosis is made with plain radiographs [5]. On bone scintigraphy, slightly increased activity can be seen, which represents active osseous remodeling at the site of the lesions, but it usually shows no abnormalities. Therefore, an abnormal scan does not preclude the diagnosis of osteopoikilosis if characteristic findings are shown on bone scintigraphy $[5,10]$.

The differential diagnoses for osteopoikilosis are extensive. The most important ones being tuberous sclerosis, mastocytosis, and osteoblastic metastasis. Sclerotic lesions of tuberous sclerosis are mostly found in the axial skeleton with the highest frequency being in the spine. Sometimes bone cysts are also found in tuberous sclerosis, which are not associated with osteopoikilosis [11]. Osseous macrocytosis presents as scattered, non-homogenous sclerotic lesions with lytic foci, predominantly in the epiphyses of long bones. The skin is usually the first organ to be involved [12]. Osteoblastic lesions are irregular and have a predilection for the axial skeleton. It presents with osseous destruction, periosteal reaction, and positive findings on bone scintigraphy.

Osteopoikilosis is usually asymptomatic, but $15-20 \%$ of patients present with joint pain and joint effusion [5, 7]. It is typically discovered incidentally on radiographic imaging. Occasionally, it has been associated with heart and renal malformations, or endocrine disorders such as diabetes. Cutaneous lesions have been observed in $25 \%$ of osteopoikilosis patients [5]. It is also associated with Buschke-Ollendorf syndrome, which is a hereditary disorder characterized by skin growths called connective tissue nevi and bone abnormalities such as osteopoikilosis and melorheostosis. Other skin conditions that coexist with osteopoikilosis include keloids, scleroderma-like lesions, and discoid lupus erythematosus [8, 13]. Several autoimmune disorders such as rheumatoid arthritis, systemic lupus erythematosus, reactive arthritis, ankylosing spondylitis, psoriatic arthritis, familial Mediterranean fever, dacryocystitis, scleroderma, fibromyalgia, and Quervain's syndrome can coexist with osteopoikilosis. Malignant transformation is very rare, but there have been cases of malignancies such as osteosarcoma, giant cell tumors, and chondrosarcoma [14]. Regular follow up imaging is not recommended.

Osteopoikilosis usually is benign, but if pain develops, NSAIDs may be used. Sometimes other pain medications such as acetaminophen and opioids can also be considered. Active lesions have been treated with bisphosphonate therapy, but the results are controversial [7]. We believe that our patient was asymptomatic from his osteopoikilotic lesions and was instead suffering from rotator cuff tendinopathy. He was offered the usual treatment for this condition and reassurance about the abnormal radiographic findings.

In conclusion, when multiple bone lesions are discovered on radiographic imaging, regardless of symptomology, osteopoikilosis might be considered in the differential diagnosis. As it is a benign bone disorder, it requires no treatment or further unnecessary investigations. Patient education and reassurance are key components of the management and treatment.

\section{Conflict of interest}

The authors declare that there is no conflict of interest.

\section{Disclaimer}

This research was supported (in whole or in part) by HCA Healthcare and/or an HCA Healthcare affiliated entity. The views expressed in this publication represent those of the author(s) and do not necessarily represent the official views of HCA Healthcare or any of its affiliated entities.

\section{Source of funding}

This case report did not receive any specific grant from funding agencies in the public, commercial, or not-for-profit sectors.

\section{References}

[1] Bull M, Calderbank P, Ramachandran N (2007). "A cause for concern? Osteopoikilosis found incidentally in the emergency department: a case report". Emerg Med J. 24 (5): e29. doi:10.1136/emj.2006.045765. PMC 2658513. PMID 17452689. https://doi.org/10.1136/emj.2006.045765.

[2] Benli IT, Akalin S, Boysan E, Mumcu EF, Kis M, Turkoglu D. Epidemiological, clinical and radiological aspects of osteopoikilosis [Erra-tum appears in J Bone Joint Surg [Br] 1994 Jul;76(4):683]. J Bone Jt Surg Br 1992;74(4):504-6. https://doi.org/10.1302/0301-620X.74B4.1624505.

[3] Ghai S, Sharma R, Ghai S (2003) Mixed sclerosing bone dysplasia-a case report with literature review. Clin Imaging 27(3):203-205. https://doi.org/10.1016/S0899-7071(02)00516-8.

[4] Sotoude H, Arshadi A, Mohebbi Z, Tamri S, \& Mozafari R. (2018). Accidental finding in an accident. Internal and emergency medi-cine, 13(3), 459460. https://doi.org/10.1007/s11739-017-1766-x.

[5] Korkmaz MF, Elli M, Özkan MB, Bilgici MC, Dağdemir A, Korkmaz M, \& Tosun FC. (2015). Osteopoikilosis: report of a familial case and review of the literature. Rheumatology international, 35(5), 921-924. https://doi.org/10.1007/s00296-014-3160-6.

[6] Carpintero P, Abad JA, Serrano P, Serrano JA, Rodriguez P, Castro L. Clinical features of ten cases of osteopoikilosis. Clin Rheumatol 2004;23(6):505-8. https://doi.org/10.1007/s10067-004-0935-2.

[7] Woyciechowsky TG, Monticielo, MR, Keiserman B, Monticielo OA. Osteopoikilosis: what does the rheumatologist must know about it? Clin Rheumatol 2012; 31: 745-48. https://doi.org/10.1007/s10067-011-1916-x.

[8] Szabo AD. Osteopoikilosis in a twin. Clin Orthop and Related Research. 1971; 79: 156. https://doi.org/10.1097/00003086-197109000-00023.

[9] Jonasch E. (1955, March). 12 Fälle von osteopoikilie. In RöFo-Fortschritte auf dem Gebiet der Röntgenstrahlen und der bildgebenden Verfahren (Vol. 82, No. 03, pp. 344-353). @ Georg Thieme Verlag KG Stuttgart. New York. https://doi.org/10.1055/s-0029-1212549.

[10] Serdaroğlu M, Çapkın E, Üçüncü F, \& Tosun M. (2007). Case report of a patient with osteopoikilosis. Rheumatology international, 27(7), 683-686. https://doi.org/10.1007/s00296-006-0262-9.

[11] Brakemeier S, Vogt L, Adams LC, Zukunft B, Diederichs G, Hamm B, ... \& Makowski MR. (2018). Sclerotic bone lesions as a potential imaging biomarker for the diagnosis of tuberous sclerosis complex. Scientific reports, 8(1), 953. https://doi.org/10.1038/s41598-018-19399-7.

[12] Barer M, Peterson LF, Dahlin DC, Winkelmann RK, \& Stewart JR. (1968). Mastocytosis with osseous lesions resembling metastatic ma-lignant lesions in bone. JBJS, 50(1), 142-152. https://doi.org/10.2106/00004623-196850010-00009.

[13] Hill CE, \& McKee L. (2015). Osteopoikilosis: An important incidental finding. Injury, 46(7), 1403-1405. https://doi.org/10.1016/j.injury.2015.02.005.

[14] Du Mortier A, \& Docquier PL. (2014). Traumatic fracture in a patient with osteopoikilosis. Case reports in orthopedics, 2014. https://doi.org/10.1155/2014/520651. 